Link to published version in the journal format:

http://link.springer.com/article/10.1007/s12469-013-0061-0

For Citation please use: Diab, E., \& El-Geneidy, A. (2013). Variation in bus transit service: Understanding the impacts of various improvement strategies on transit service reliability. Public Transport: Planning and Operations, 4(3), 209-231.

\title{
Variation in bus transit service: Understanding the impacts of various improvement strategies on transit service reliability
}

\author{
Ehab I. Diab \\ Ph.D. student \\ School of Urban Planning \\ McGill University \\ Suite 400, 815 Sherbrooke St. W. \\ Montréal, Québec, H3A 2K6 \\ Canada \\ Tel.: 514-549-0093 \\ Fax: 514-398-8376 \\ E-mail: ehab.diab@mail.mcgill.ca \\ Ahmed M. El-Geneidy
Associate Professor
School of Urban Planning
McGill University
Suite 400, 815 Sherbrooke St. W.
Montréal, Québec, H3A 2K6
Canada
Tel.: 514-398-8741
Fax: 514-398-8376
E-mail: ahmed.elgeneidy@mcgill.ca
}

January 2013

Transportation Research at McGill (TRAM)

School of Urban Planning McGill University 


\begin{abstract}
Transit agencies wishing to offer reliable service with less variability compared to schedules face several challenges, encouraging them to employ various strategies. While previous research has considered the effects of various strategies on running time, there has been little effort to understand their impacts on reliability of service. This article examines the impacts of various improvement strategies, implemented by Société de Transport de Montréal (STM) along one of its heavily utilized bus routes, on running time deviation from schedule, variation in running time, and variation in running time deviation from schedules. These strategies have been implemented at different time points over past 3 years. They include, chronologically ordered, implementation of a smart card fare collection system, operation of a reserved bus lane, introduction of limited-stop bus service, use of articulated buses, and operation of transit signal priority (TSP). This study uses automatic vehicle location (AVL) and automatic passenger count (APC) systems at the bus route segment level of analysis. The introduction of a smart card fare collection system increased bus running time and service variation. Articulated buses, limitedstop bus service and reserved bus lanes have mixed effects on variation in comparison to the running time changes, while TSP did not show an impact on variations in our study. This study offers transit agencies and schedulers a better understanding of the effects of various strategies on different aspects of service variation, which are important components of transit service reliability.
\end{abstract}

Keywords: bus service, running time variation, limited-stop bus service, articulated buses, reserved lane, smart card fare collection, transit signal priority (TSP) 


\section{Introduction}

Transit agencies implement various strategies in order to enhance service and provide transportation that can compete with other transport modes, such as private automobile. Between 2008 and 2011, the Société de Transport de Montréal (STM), which operates the transit service on the island of Montreal, Canada, considered various measures for improving bus service along the corridor of Saint Michel. This corridor is receiving special attention from the STM since it is a heavily used bus corridor, with an average total daily ridership of 43,000 passengers. The measures implemented by STM started in April 2008 with the introduction of a new smart card fare collection system named OPUS. OPUS replaced the traditional flash passes and provided passengers with a more appealing and convenient payment option (Société de transport de Montréal, 2010). At the end of March 2009, the STM introduced a limited-stop service named Route 467 running parallel to the regular service of Route 67 along the corridor, serving only $40 \%$ of the regular route stops. Both regular and new bus routes have an average headway of 7 minutes during peak hours. At the beginning of August 2009, the STM introduced reserved lanes functioning during peak hours, aiming to improve the service efficiency along the corridor. Starting at the beginning of February 2010, the STM operated several articulated buses along Route 467. Finally, in September 2010, the STM outfitted a few articulated buses along route 467 with a transit signal priority (TSP) system, giving these buses priority over other road vehicles at all corridor signals. Figure 1 presents a timeline of the strategies implemented by the STM along the studied routes between January 2007 and April 2011. STM implemented some of these strategies with the goals of improving running time and increasing customer comfort, ease of using the system and satisfaction.

This temporal difference between the implemented strategies offers a unique opportunity to understand their impacts on service attributes and examine the synergies between them. Previous efforts by the authors investigated the overall impacts of these strategies on running time at the route level (Diab \& El-Geneidy, 2012), which was one of the main goals these strategies were implemented for. However, this information presented only one important part of the picture and ignored any side effect that the strategies could have on variation in the service. The effect of these strategies on service variation is an important aspect of service provision. Transit agencies pay a lot of attention to variation of transit service since the variation affects directly the amount of recovery time added to schedules and service productivity. Transit agencies are also interested in providing reliable service that is fast and consistent from day to day to increase passenger satisfaction with service. This is due to the fact that passengers are concerned about the day-to-day variability in bus service performance, which affects their decision-making and time-planning processes. Additionally, an increase in service variation can result in the need of adding new buses to maintain the same level of frequency, whereas a reduction in variation can offer the opportunity to add additional trips since recovery time added to schedules are reduced.

This paper aims to provide an understanding of the impacts of various measures implemented by the STM on bus running time variation. It also aims to understand bus running time variation in relation to schedules at the segment level. This study employs a wide array of archived data obtained from the STM's automatic vehicle location (AVL) and automatic passenger count (APC) systems for Route 67 and Route 467. The paper starts with a literature review on the effects of various measures on both running time and running time variation, 
followed by a methodology section describing the data and methods used. This is followed by an analysis section including the results of the models with a detailed discussion. Finally, the paper ends with a conclusion section outlining the major findings of this paper and its policy implication for transit planners and operators.

\section{Literature review}

While bus transit service is the dominate type of public transit in most of Canadian and USA cities (American Public Transportation Association, 2011a, 2011b), it is also the most sensitive transit service in terms of being subject to expected and unexpected events (ElGeneidy, Strathman, Kimpel, \& Crout, 2006; Kimpel, 2001; Kittelson \& Associates, KFH Group, Parsons Brinckerhoff Quade \& Douglass, \& Hunter-Zaworsk, 2003; Strathman et al., 2000). Transit agencies are challenged to provide attractive services for bus transit users. Passengers are concerned about the day-to-day variability in bus service performance, considering transit to be more reliable only when it (a) decreases their efforts to access the service at both origin and destination (Hensher, Stopher, \& Bullock, 2003; Murray \& Wu, 2003); (b) have a low waiting time at stops; (c) and their travel time is short and consistent from day to day (El-Geneidy, Horning, \& Krizek, 2011; Koenig, 1980; Murray \& Wu, 2003).

Researchers indicate that the values people place on travel time and travel time variation were found to be nonlinear (Pinjari \& Bhat, 2006). The cost of travel time variation may in fact be greater than the cost of regular travel time (C. Chen, Skabardonis, \& Varaiya, 2003; Perk, Flynn, \& Volinski, 2008), greatly affecting decision-making and daily time planning processes (Bates, Polak, Jones, \& Cook, 2001; Nam, Park, \& Khamkongkhun, 2005; Noland \& Polak, 2002). Increases in service variation for users are associated with increases in their waiting times at bus stops increasing their anxiety levels and reduce the perceived comfort, which result in decreasing attractiveness of the service (Bates et al., 2001; Perk et al., 2008). Researchers indicate that a service with smaller deviations in relation to schedule is more appreciated by the public than a shorter headway service (Balcombe et al., 2004; Daskalakis \& Stathopoulos, 2008). Balcombe et al. (2004) state that passengers consider service reliability twice as important as bus frequency Furthermore, improvement in service running time and running time variability have both been linked to increases in ridership and riders satisfaction levels (Boyle, 2006; Hensher et al., 2003; Hollander, 2006).

Running time is the amount of time that it takes for a bus to travel from point A to B along a designated route serving passengers. Various basic factors have been identified by researchers as affecting bus running time. These factors include distance, passenger activity (passenger boardings and alighting), routes' built environment (such as number of signalized intersections), delay at the start, period of the day, number of actual stops made, environmental factors (such as rain and snow), and traffic conditions (Abkowitz \& Engelstein, 1983; ElGeneidy et al., 2011; Levinson, 1983; Strathman et al., 2000). These factors are also strongly believed to influence running time variability (Abkowitz, 1983; El-Geneidy et al., 2011; Kimpel, 2001; Sterman \& Schofer, 1976). Accordingly, agencies implementing different strategies, such as smart card fare collection systems, reserved bus lanes, limited-stop bus services, articulated buses, and TSP, are expecting an impact on both running time and running time variation (Tann \& Hinebaugh, 2009). 
Many researchers have investigated the effects of different strategies on running time (Diab \& El-Geneidy, 2012; El-Geneidy et al., 2011; Kimpel, Strathman, Bertini, Bender, \& Callas, 2005; Surprenant-Legault \& El-Geneidy, 2011). Meanwhile, less attention has been given to the impacts of these strategies on the variation of service since variation is more difficult to address (Schramm, Watkins, \& Rutherford, 2010). Several studies agreed that limited-stop bus service and reserved bus lane decrease running time (El-Geneidy \& Surprenant-Legault, 2010; Surprenant-Legault \& El-Geneidy, 2011), while TSP systems have uncertain effects on running time (Kimpel et al., 2005). The use of articulated buses along a transit corridor is expected to have a mixed effect on running time. The first is a negative effect increasing running time due to the acceleration, deceleration and maneuvering time. The second is a positive effect decreasing running time due to the decline in the time associated to passenger activity (El-Geneidy et al., 2011). The use of the smart card have a general negative effect increasing running time compared to using flash passes (El-Geneidy \& Surprenant-Legault, 2010; Kittelson \& Associates et al., 2003; Surprenant-Legault \& El-Geneidy, 2011).

To understand the effect of various strategies on running time, researchers generated running time models and analyzed the effects of these measures using before and after AVL/APC archived data through isolating the impacts of each strategy. Using AVL/APC data is common in the transit literature (El-Geneidy et al., 2006; Kimpel, 2001; Kimpel et al., 2005). Other researchers focused on generating performance measures that determine and accommodate the service variability. For example, Camus et al. (2005) proposed a new measure named Weighted Delay Index to overcome a shortcoming of on time performance (OTP), which is recommended by the transit capacity and quality of service manual (TCQSM), in order to better understand the service reliability (Kittelson \& Associates et al., 2003). Lin et al. (2008) used AVL data and a framework involving Data Envelopment Analysis (DEA), to generate a comprehensive measure of service reliability. Using different methodology, similar research has been done by Fu et al. (2007) to present a measure called Transit Service Indicator (TSI), combining multiple performance measures. Later on, Chen et al. (2009) and Saberi et al. (2012) generated different measures to assess the service variation and reliability.

Other researchers focused on understanding the general factors affecting the variation through simple measures of variation (Abkowitz, 1983; El-Geneidy et al., 2011). The work of Abkowitz and Engelstein (1983) was among the earliest studies on running time variation. They investigated running time variation at the route-segment level of analysis, and they found that variation tends to escalate as vehicles move along a route, having included a variable to control for the existing levels of variation. Kimple (2001), using AVL/APC from TriMet, Portland, provided a framework for analyzing transit service reliability and especially variation at the time point level of analysis, and incorporated headway delay variation and departure delay variation as measures. He found that the amount of delay variation at the previous time point affects the amount of headway delay variation and departure delay variation. Later, one study analyzed AVL data obtained from Metro Transit, Minnesota, by using running time deviation and the coefficient of variation (CV) of running time models (El-Geneidy et al., 2011).

However, none of the aforementioned studies have focused on understanding the impacts of the implementation of various strategies on service variation. One study by El-Geneidy et al. (2006) used AVL/APC data from TriMet to analyze bus service variation after the 
implementation of a bus stop consolidation project, using running time and CV of running time model, while controlling different influential variables. They revealed that while running time had improved by $6 \%$ at the segment level, there was no evidence of any changes in running time variation, which can be associated to the length of the segment being studied. Other studies used simple descriptive statistics to understand the impact of the implementation of TSP (Kimpel et al., 2005) and to address various bus rapid transit (BRT) features on running time variation (Schramm et al., 2010), without isolating different influential variables' effects on the service. Therefore, further investigation on the effect of the use of smart cards, limited-stop bus service, articulated buses, TSP and reserved lanes on variation is required.

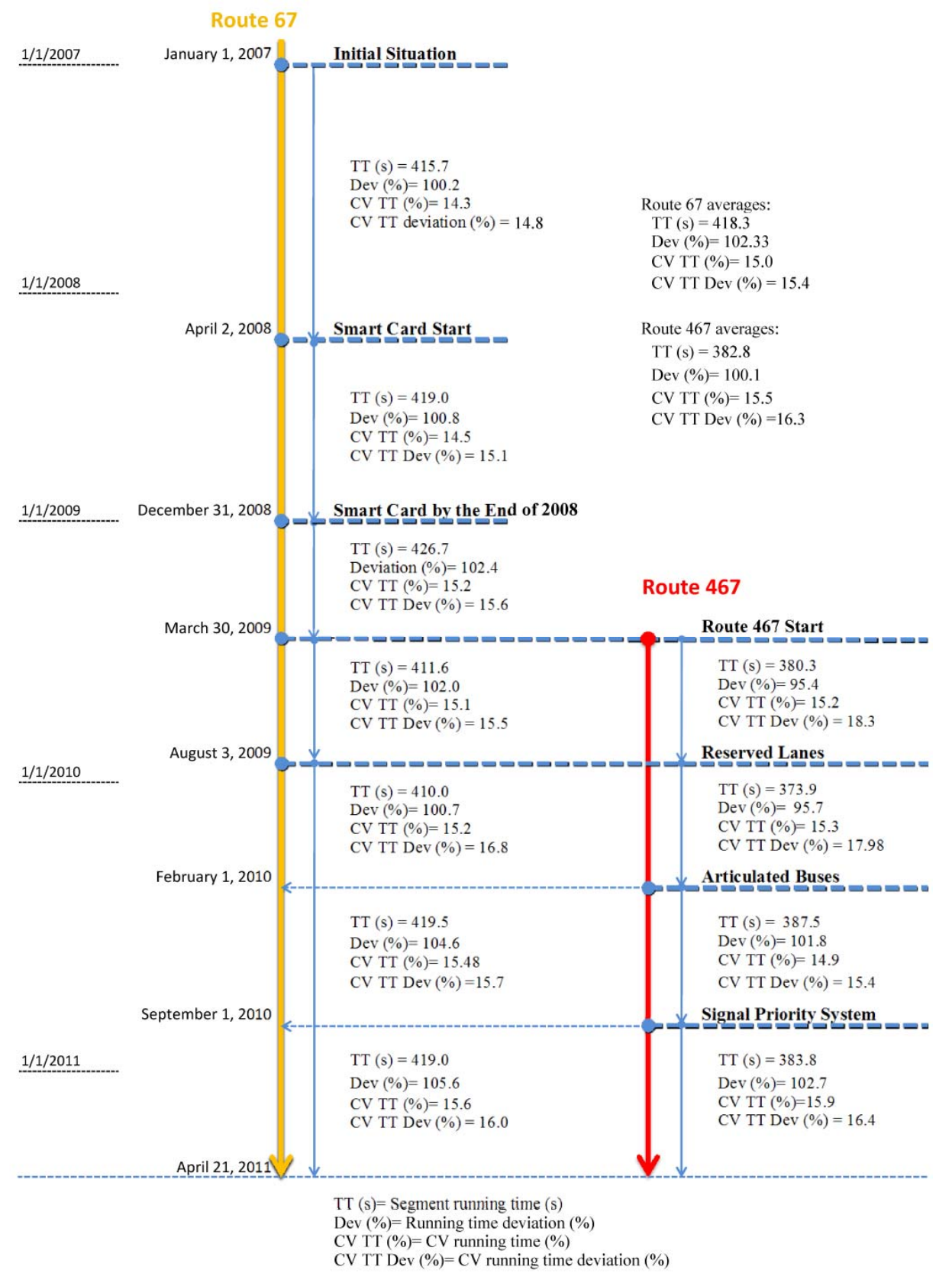

Figure 1: Time line of changes done to bus service on Boulevard Saint Michel 


\section{Methodology}

The objective of this analysis is to understand the effect of various strategies implemented by STM on buses' travel time variation and deviation from the schedule at the segment level. The data used in the analysis comes from a sample of STM's AVL and APC archived data system for routes 67 and 467. As only around 18\% (306 out of 1,680 buses) of STM's buses are equipped with AVL and APC systems, the STM operates these buses in different routes in order to understand its overall service quality and to adjust schedules. Routes 67 and 467 run for approximately $9.4 \mathrm{~km}$ along the eastern side of Montreal's Central Business District (CBD) area. They cross through five boroughs of the City of Montreal, and connect two metro stations. The routes share Boulevard Saint-Michel which consists of three lanes in each direction. The built environment along the Boulevard mainly consists of two to three floors residential building with more concentration of commercial uses associated with parking lots and storage areas at the north direction. There were no significant changes around the corridor during the last five years in terms of the built environment. The average stop spacing is 615 meters for Route 467, while it is 245 meters for Route 67. Figure 2 shows Route 467 and Route 67 as well as the analyzed segments. All signalized intersections are equipped with TSP along the analyzed segments, which extend the green lights or activate the priority system for outfitted TSP buses (Société de Transport de Montréal, 2011). The reserved bus lane is located on the far right lane along each direction near to pedestrian sidewalks, designated with paint and signage. It is, however, allowed for private automobiles to use these reserved lanes during operation hours to turn right. Different types of intersections can be found across the boulevard from 3-way intersections (including $\mathrm{T}$ intersections and $\mathrm{Y}$ intersections) to 4-way intersections.

Over 2,250,000 individual stop observations for routes 67 and 467 were collected from the STM's archival data between January $1^{\text {st }}, 2007$ and April $21^{\text {st }}, 2011$. Individual stop data includes bus arrival, departure, and schedule times along the route, as well as information about passenger activity and load, trip number and direction, and bus type. Since trip segment is the paper's unit of analysis, all variables were summarized according to trip segment, for example passenger activity per trip segment. After cleaning the source data and removing system recording errors, holiday and weekend trips, layover time and segments with insufficient passenger activity (less than 3 passenger per trip segment (less than $1 \%$ of the total number of trip segments)), 255,000 trip segments were included in the final database. For each of these trip segments percentage of running time deviation from schedule has been calculated by dividing actual running time per trip segment by scheduled running time per trip segment, and afterwards, multiplying the outcome by one hundred.

The objective of this analysis is to understand the effect of each strategy implemented by STM on bus travel time variation and deviation variation from the schedule at the segment level of analysis. Data from the trip segments have been aggregated according to the following criteria: the implemented strategy, time of the day (am peak, pm peak, midday, night, and midnight or early morning), type of bus (articulated or regular buses), route number (route 467 or 67), and direction (north or south). For example, all Route 467 northbound trips done by regular buses using the reserved lanes, during the afternoon peak, after the introduction of articulated buses along the corridor and before the implementation of TSP system, along the first segment, are aggregated into one category in order to understand their travel time range of variation. This is done by calculating the average and standard deviation of running time for this group of trips 
and then calculating the $\mathrm{CV}$ of running time, and the $\mathrm{CV}$ of running time deviation, from the schedule. Furthermore, to ensure robustness of the generated data, several sample sizes were tested to distinguish how many trip segments at minimum should be included to derive the group averages and standard deviations. A group of 25 trip segment observations was found to be a good threshold for a group to maintain its robustness. Accordingly, after this process, 478 groups of trip segments were kept. The included groups in analysis represent more than $99 \%$ of all trip segment observations with an average group size of 530 trip segment observations. The following formulas describe the previous calculations:

$$
\begin{aligned}
& \text { Running time deviation }(\%)= \begin{array}{c}
\text { (the actual running time per trip segment } / \text { the } \\
\text { scheduled running time per trip segment }) * 100
\end{array} \\
& \text { CV Running time }(\%)= \begin{array}{c}
\text { (running time standard deviation for a group } / \text { the } \\
\text { group average running time }) * 100
\end{array} \\
& \text { CV running time deviation }(\%)=\begin{array}{c}
\text { (running time deviation standard deviation for a } \\
\text { group / running time deviation average }) * 100
\end{array}
\end{aligned}
$$

In this research we will be concentrating on four statistical models to capture and isolate the effects of the improvement strategies made by STM on bus running time variation and variation of deviation from schedule. A detailed description of each variable used in the models is presented in Table 1. The first model is the trip segment running time model. The purpose of the model is to understand the overall quality of data used in this study, to identify its consistency with previous research discussed in literature, and to demonstrate the effects of the improvement strategies made by STM during the study period at the segment level. According to previous studies, the general factors affecting running time include passenger activity, distance, passenger activity associated with articulated buses, number of stops made, time of the day, delays at the beginning of a trip, bus type and weather conditions (Abkowitz \& Engelstein, 1983; Diab \& El-Geneidy, 2012; Kimpel, 2001). A dummy for segment number is included in the models in order to isolate the built environment and land use, intersection, distance and corridor design effects on bus running time and variation. Furthermore, various dummy variables have been generated to control the implemented strategies by STM impacts, including the introduction of a smart card system, limited-stop service, reserved lanes, articulated buses and TSP system.

Two dummies have been included in the models to demonstrate the real effect of using a smart card system. The first dummy is Smart card start, distinguishing the trips made after the introduction of the new smart card system in April 2008. The second dummy is smart card by the end 2008, distinguishing the trips made after the widespread use of the new smart card, since according to official reports around a half million cards were functioning by the end of 2008 (Société de transport de Montréal, 2009). In addition, a dummy variable called Reserved lanes is included in the models, distinguishing trips that utilized the reserved lane. The reserved lanes are operated according to time and direction, from 2:30 P.M. to 6:30 P.M northbound and from 6:30 A.M. to 9:00 A.M. southbound. Articulated buses and TSP buses are two dummy variables that are included also in the models, to recognize articulated buses and buses outfitted with a TSP system, respectively. Finally, two dummy variables, After articulated buses date and After TSP date are included, distinguishing all the trips made after the date of the introduction of the articulated buses and the TSP system along the corridor, respectively. These two variables would help in identifying the effect of implementing articulated buses and TSP equipped buses serving Route 467 on all buses running along the corridor, including Route 67 buses. 
The second model is the running time deviation percentage model, showing the effects of STM implemented strategies on running time in relation to the associated schedules, allowing us to recognize the real quality of service that people are experiencing. The third model is the CV of running time (\%) model, which measures and captures the effect of the implemented strategies on running time variation which is mostly appreciated by passengers, while controlling different influential variables. The fourth model is CV of running time deviation (\%), which captures the difference between the trip segments' running time range of variation and the schedules' permitted level of variation after every implemented strategy by STM. 


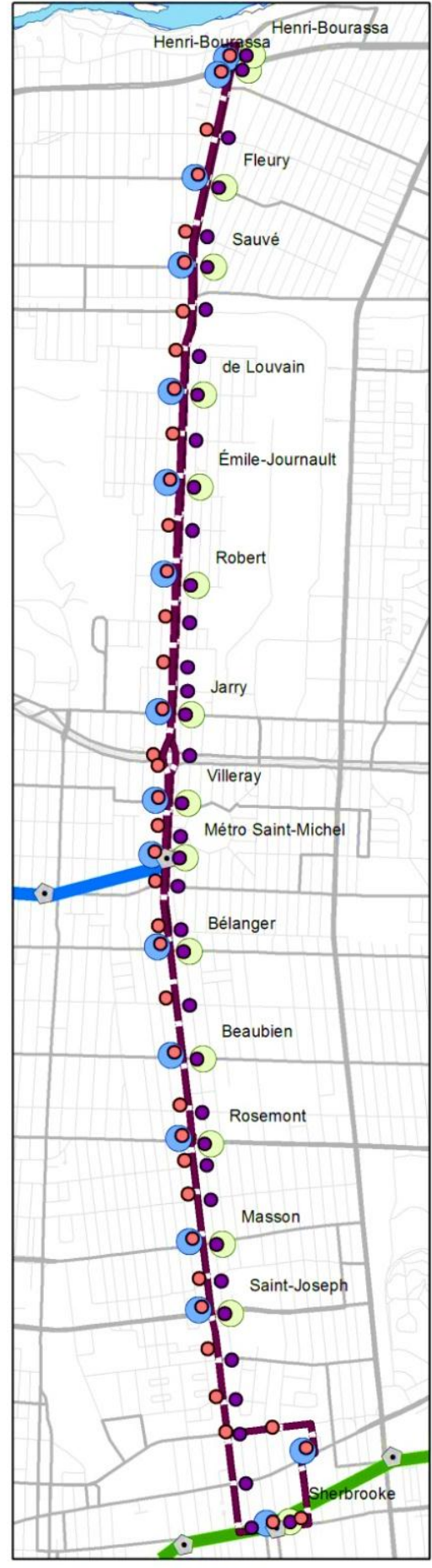

Data Source: STM \& DMTI
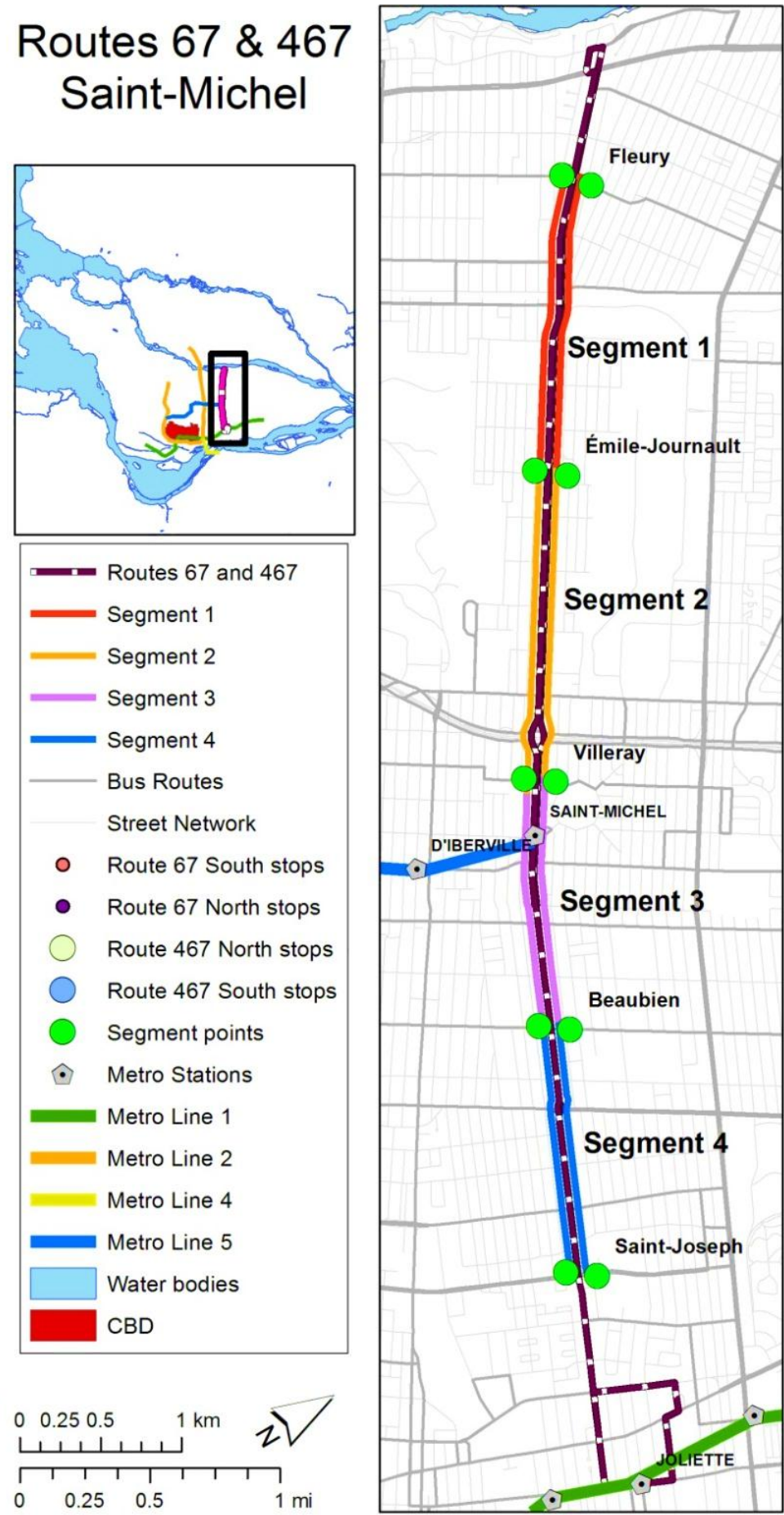

Projection: NAD 1983 MTM 8

Figure 2: Study route segments 
Table 1: Description of variables used in the regression models

\begin{tabular}{|c|c|}
\hline Variable Name & Description \\
\hline $\begin{array}{l}\text { Segment running time } \\
\text { (seconds) }\end{array}$ & $\begin{array}{l}\text { The segment running time in seconds, which is the difference between } \\
\text { leave time from the last stop of a segment and the leave time of the first } \\
\text { stop of a segment for a designated trip. }\end{array}$ \\
\hline $\begin{array}{l}\text { Segment running time } \\
\text { deviation }(\%)\end{array}$ & $\begin{array}{l}\text { The actual running time divided by the scheduled running time multiplied } \\
\text { by one hundred. }\end{array}$ \\
\hline Route 467 & A dummy variable equaling one if the trip segment occurs on Route 467. \\
\hline Northbound & Dummy variable for northbound trips. \\
\hline Segment passenger activity & Total number of passenger boardings and alightings per trip segment. \\
\hline Articulated rear door activity & $\begin{array}{l}\text { Total number of passenger boardings and alightings from articulated buses } \\
\text { third door per trip segment. }\end{array}$ \\
\hline Actual stops & Number of the actual stops made per trip segment. \\
\hline Precip (mm) & $\begin{array}{l}\text { The average of rainfall measured in millimeters on a day of the trip } \\
\text { segment. }\end{array}$ \\
\hline Snow $(\mathrm{cm})$ & Snow precipitations in centimeters that took a place during the trip day. \\
\hline Delay at the start (s) & $\begin{array}{l}\text { The delay at the start of a trip segment in seconds, which is the difference } \\
\text { between the leave time and the scheduled leave time at the first stop of a } \\
\text { segment. }\end{array}$ \\
\hline AM Peak & $\begin{array}{l}\text { A dummy variable equaling one if the trip segment occurred between 6:30 } \\
\text { am to 9:30 am and zero otherwise. }\end{array}$ \\
\hline Midday & $\begin{array}{l}\text { A dummy variable equaling one if the trip segment occurred between } \\
\text { 9:30am to 3:30 pm and zero otherwise }\end{array}$ \\
\hline PM Peak & $\begin{array}{l}\text { A dummy variable equaling one if the trip segment occurred between 3:30 } \\
\text { pm and 6:30 pm and zero otherwise. }\end{array}$ \\
\hline Night & $\begin{array}{l}\text { A dummy variable equaling one if the trip segment occurred between } 6: 30 \\
\text { pm to } 12: 00 \text { am and zero otherwise. }\end{array}$ \\
\hline Midnight and early morning & $\begin{array}{l}\text { A dummy variable equaling one if the trip segment occurred between 12:00 } \\
\text { am and 6:30 am and zero otherwise. }\end{array}$ \\
\hline Smart card & $\begin{array}{l}\text { A dummy variable equaling one if the data used for this trip segment were } \\
\text { collected after the implementation of a new smart card fare collection } \\
\text { system named OPUS on April 1st, } 2008 \text { and zero otherwise. }\end{array}$ \\
\hline Smart card by the end of 2008 & $\begin{array}{l}\text { A dummy variable equaling one if the data used for this trip segment were } \\
\text { collected after the December 31st, } 2008 \text { and zero otherwise, distinguish the } \\
\text { spread of OPUS use. }\end{array}$ \\
\hline Reserved lane & $\begin{array}{l}\text { Dummy variable equaling one if the data used for this trip segment were } \\
\text { collected after August 3, 2009, and between 6:30 A.M. and 9:00 A.M. } \\
\text { southbound or between 2:30 P.M. and 6:30 P.M. northbound. }\end{array}$ \\
\hline After articulated buses date & $\begin{array}{l}\text { A dummy variable equaling one if the data used for this trip segment were } \\
\text { collected after the introduction of articulated buses along Saint-Michel } \\
\text { corridor on February } 1^{\text {st }}, 2010 \text {. }\end{array}$ \\
\hline Articulated buses & A dummy variable equaling one if the bus is articulated and zero otherwise. \\
\hline After TSP date & $\begin{array}{l}\text { A dummy variable equaling one if the if the data used for this trip segment } \\
\text { were collected after the use of } \\
\text { TSP equipped buses along Saint-Michel corridor on September } 1^{\text {st }}, 2010 \text {. }\end{array}$ \\
\hline TSP buses & $\begin{array}{l}\text { A dummy variable equaling one if the bus is TSP equipped and zero } \\
\text { otherwise. }\end{array}$ \\
\hline Segment 1 & $\begin{array}{l}\text { A dummy variable equaling one if the trip occurred between Fleury and } \\
\text { Emile-Journault bus stops either for north or south directions (extending for } \\
1820 \text { meters on average) and zero otherwise. }\end{array}$ \\
\hline
\end{tabular}




\begin{tabular}{ll}
\hline Variable Name & Description \\
\hline Segment 2 & $\begin{array}{l}\text { A dummy variable equaling one if the trip occurred between Emile- } \\
\text { Journault and Villeray bus stops either for north or south directions } \\
\text { (extending for } 1912 \text { meters on average) and zero otherwise. }\end{array}$ \\
A dummy variable equaling one if the trip occurred between Villeray and \\
Beaubien bus stops either for north or south directions (extending for 1554 \\
meters on average) and zero otherwise. \\
A dummy variable equaling one if the trip occurred between Beaubien and \\
Saint-Joseph bus stops either for north or south directions (extending for
\end{tabular}

\section{Analysis}

\subsection{Descriptive statistics}

Table 2 presents summary statistics for the variables used in this study at disaggregated trip segments and at aggregated grouped trip segment levels. For Route 467, the average trip segment's running time is 382 seconds (6.36 minutes) with standard deviation of 75 seconds, while the average for Route 67 is 418 seconds (6.96 minutes) with standard deviation of 81 seconds. This indicates that route 467 is faster than route 67 with less variation in travel time. The running time deviation percentage average for Route 467 is $100.1 \%$, with standard deviation of 22.8\%. Meanwhile, for Route 67, the average running time deviation is $102.3 \%$, with standard deviation of $18.4 \%$. This indicates that on average the actual running time for Route 467 is slightly longer than the scheduled running time by $0.1 \%$, while for Route 67 is longer by $2.3 \%$.

For route 467 the average coefficient of variation of running time per grouped trip segment is $15.5 \%$, while for Route 67 , the variation from the average is $15 \%$. This indicates that while Route 467 is much faster than Route 67 it has more variation in running time in relation to the running time mean value. Furthermore, the coefficient of variation of running time deviation for Route 467 is $16.3 \%$, while for Route 67 the average is $15.4 \%$. This indicates more variation in delays for Route 467 than for Route 67. Nevertheless, in order to understand how every strategy implemented by the STM along the corridor affects buses' running time, running time variation and deviation from the schedules at the segment level, four statistical models are presented in the following section. 
Table 2: Descriptive Statistics

\begin{tabular}{|c|c|c|c|c|c|c|}
\hline \multirow[b]{2}{*}{ Variable } & \multicolumn{2}{|c|}{ All data } & \multicolumn{2}{|c|}{ Route 67} & \multicolumn{2}{|c|}{ Route 467} \\
\hline & Mean & $\begin{array}{c}\text { Std. } \\
\text { Deviation }\end{array}$ & Mean & $\begin{array}{c}\text { Std. } \\
\text { Deviation }\end{array}$ & Mean & $\begin{array}{c}\text { Std. } \\
\text { Deviation }\end{array}$ \\
\hline Segment running time (seconds) & 408.8 & 81.4 & 418.3 & 81.6 & 382.8 & 75.0 \\
\hline Segment runtime deviation (\%) & 101.7 & 19.7 & 102.3 & 18.4 & 100.1 & 22.8 \\
\hline Segment scheduled running time & 406.0 & 62.4 & 411.2 & 54.9 & 391.9 & 77.7 \\
\hline Segment passenger activity & 32.5 & 18.7 & 33.7 & 18.5 & 29.3 & 19.0 \\
\hline Articulated rear door activity & 0.7 & 2.5 & 0.0 & 0.0 & 2.8 & 4.3 \\
\hline Actual stops made & 5.0 & 1.7 & 5.8 & 1.3 & 2.9 & 0.3 \\
\hline Northbound & 0.5 & 0.5 & 0.5 & 0.5 & 0.6 & 0.5 \\
\hline Southbound & 0.5 & 0.5 & 0.5 & 0.5 & 0.4 & 0.5 \\
\hline Route 467 & 0.3 & 0.3 & 0.0 & 0.0 & 1.0 & 0.0 \\
\hline Route 67 & 0.7 & 0.3 & 1.0 & 0.0 & 0.0 & 0.0 \\
\hline Delay at the start (s) & 54.3 & 123.2 & 54.9 & 124.5 & 52.8 & 119.5 \\
\hline Delay at the end (s) & 57.1 & 143.1 & 62.0 & 144.9 & 43.7 & 136.9 \\
\hline Distance (meter) & 1704.3 & 165.4 & 1704.5 & 165.5 & 1703.6 & 165.2 \\
\hline Speed (KM) & 15.5 & 2.9 & 15.1 & 2.7 & 16.5 & 3.2 \\
\hline Precip (mm) & 2.9 & 6.5 & 2.9 & 6.2 & 3.1 & 7.3 \\
\hline Snow $(\mathrm{cm})$ & 3.2 & 7.0 & 3.5 & 7.4 & 2.4 & 5.5 \\
\hline Initial situation & 0.2 & 0.4 & 0.2 & 0.4 & 0.0 & 0.0 \\
\hline Smart card start & 0.8 & 0.4 & 0.8 & 0.4 & 1.0 & 0.0 \\
\hline Smart card by the end of 2008 & 0.7 & 0.5 & 0.6 & 0.5 & 1.0 & 0.0 \\
\hline Reserved lane & 0.2 & 0.4 & 0.1 & 0.3 & 0.3 & 0.5 \\
\hline After articulated buses date & 0.4 & 0.5 & 0.3 & 0.5 & 0.7 & 0.5 \\
\hline Articulated buses & 0.2 & 0.4 & 0.0 & 0.0 & 0.6 & 0.5 \\
\hline After TSP date & 0.2 & 0.4 & 0.2 & 0.4 & 0.3 & 0.5 \\
\hline TSP buses & 0.1 & 0.3 & 0.0 & 0.0 & 0.3 & 0.4 \\
\hline Number of cases & \multicolumn{2}{|c|}{255,000} & \multicolumn{2}{|c|}{186,862} & \multicolumn{2}{|c|}{68,138} \\
\hline CV running time (\%) & 15.2 & 2.1 & 15.0 & 1.8 & 15.5 & 2.4 \\
\hline CV running time deviation (\%) & 15.9 & 2.6 & 15.4 & 2.1 & 16.3 & 3.0 \\
\hline CV passenger activity (\%) & 47.7 & 7.3 & 44.7 & 4.8 & 50.4 & 8.0 \\
\hline CV articulated passenger activity (\%) & 11.6 & 15.7 & 0.0 & 0.0 & 21.7 & 18.2 \\
\hline CV actual stops (\%) & 14.9 & 6.1 & 19.5 & 4.2 & 10.7 & 4.2 \\
\hline CV precip. (\%) & 220.6 & 24.6 & 212.7 & 18.2 & 227.6 & 27.4 \\
\hline CV snow (\%) & 231.7 & 111.9 & 229.9 & 72.9 & 233.2 & 138.1 \\
\hline CV delay at the start (\%) & 214.5 & 1014 & 318.9 & 897 & 120.2 & 1103.9 \\
\hline CV delay at the end (\%) & 816.7 & 9548 & 1484 & 13752 & 212.7 & 1478.6 \\
\hline CV speed (\%) & 15.2 & 2.0 & 15.0 & 1.7 & 15.4 & 2.2 \\
\hline Number of cases & \multicolumn{2}{|c|}{478} & \multicolumn{2}{|c|}{227} & \multicolumn{2}{|c|}{251} \\
\hline
\end{tabular}




\subsection{Running time and running time deviation models}

Two linear regression models are developed for the disaggregated trip segments using running time in seconds and running time deviation by percentage as the dependent variables. Table 3 presents the results of these models. The first model, which is the segment running time model, contains 255,000 trip segments and explains $47 \%$ of the variation in running time. As expected, of the strategies introduced by STM, the implementation of limited-stop bus service, exclusive bus lane and TSP decrease running time. In contrast, the implementation of smart card systems and articulated buses increase running time. Furthermore, the presence of articulated buses along Route 467 led to an increase in running time for all buses using the corridor. While the presence of TSP outfitted buses led to decreases in running time per trip segments for all buses utilizing the corridor. These finding are consistent with previous research (Diab \& ElGeneidy, 2012; El-Geneidy et al., 2011; El-Geneidy \& Surprenant-Legault, 2010; SurprenantLegault \& El-Geneidy, 2011).

The use of articulated buses have a mixed effect on running time, increasing it due to bus acceleration and maneuvering with traffic, while decreasing it due to the third door passenger activity (El-Geneidy et al., 2011). Therefore, while total passenger activity from all buses doors increase running time by 1.62 seconds, the use of articulated buses third door decreases the average running time by 3.17 seconds per passenger along a trip segment, this indicate 1.55 seconds time saving for each passenger using the third door. Furthermore, since the average of articulated buses rear door use is 2.8 passengers (as indicated by the summary statistics), the total time saving due to the use of articulated buses third door is 8.8 seconds. Accordingly, the operation of an articulated bus will increase running time by 13 seconds at the segment level.

Each millimeter of rainfall and each centimeter of snow, increase bus running time delay by 0.1 and 0.4 seconds, respectively. Furthermore, if the bus was late at the first stop, running time is expected to be faster by 0.07 seconds for every second of delay. This indicates a recovery of $7 \%$ of delay by drivers during the trip segment, since drivers who start late compared to schedules often attempt to compensate for the delay (El-Geneidy et al., 2011; Surprenant-Legault \& El-Geneidy, 2011; Tétreault \& El-Geneidy, 2010). Compared to midday trips, the afternoon peak increases the running time by 15 seconds, while the morning peak, night time, early morning and midnight time decrease the running time by 8.2, 22.9, and 48.2 seconds. Finally, segment one, three and four are slower by 42, 73, and 92 seconds compared to segment two. This difference between segments is related to the dissimilarity in distance, built environment, and network characteristics.

The second model is the running time deviation (\%) model, which represents the actual running time per trip segment divided by the scheduled running time, multiplied by one hundred. This model is used to help in understanding the factors affecting running time deviation from schedule. The model contains 255,000 records and explains $21 \%$ of the variation in the running time deviation from schedule. This proportion of explained variance is still considered relatively high and comparable to this type of model used in literature (El-Geneidy et al., 2011). The running time deviation (\%) model is generated to understand the quality of the schedules and their relation to actual running time. Generally, it is expected that factors affecting running time deviation should have the same sign and magnitude as the previous model if schedules are adjusted correctly to address the improvement on the ground. However, the inconsistency between the two models could be interpreted in terms of adjustments needed to the schedule due 
to a specific independent variable. Furthermore, the F-Test results, not only for this model but also for all the four models, show that the F significance is almost equal to zero. Therefore, we reject the null hypothesis with extremely high confidence above $99.99 \%$, and we conclude that the independent variables as a set have a relationship with the dependent variable.

As seen in table 3, at the second model, every stop made is expected to deviate running time from schedule by 3.5\%. In addition, since the average of the actual stops made by a bus along Route 467 and 67 segments are 3 and 6 stops, respectively. That would mean a deviation of $10 \%$ and $20 \%$ from the schedules are expected. Each additional passenger boarding or alighting the bus along the segment deviates the actual running time from schedules by $0.31 \%$, while passenger activity from articulated buses' third door deviates running time by $0.67 \%$. This in part may be because the overestimated time saving that was expected by schedulers for the use of the articulated buses third door. With regard to meteorological factors, every millimeter of rainfall and centimeter of snow, deviation will increase by $0.02 \%$ and $0.1 \%$ seconds, respectively. For each second of delay at the first stop along the studied segments, running time deviation decreases by $0.02 \%$. which is consisted with previous studies (Surprenant-Legault \& El-Geneidy, 2011).

Morning peak, evening peak, night, and midnight and early morning are expected to decrease running time deviation from schedules by $0.7 \%, 3.3 \%, 1.4 \%$ and $0.3 \%$, compared to midday trips, respectively. This indicates that midday trips are usually more deviated from schedules than during other time periods. Furthermore, characteristics of the built environment also affect deviation from schedules. Segment number one, three and four decrease deviation from schedules by $6.9 \%, 0.7 \%$ and $1.2 \%$, respectively, compared to segment number two, while keeping all other variables at their mean values.

The implementation of a smart card fare collection system initially increased running time deviation by $0.8 \%$, and by $3.1 \%$ at the end of the implementation period in 2008 . This indicates that schedules did not adjust to add the extra amount of time contributed by the introduction of smart cards right away, compared to the situation before (when passengers were using the flash passes). At the segment level, the limited-stop bus service (Route 467) is generally expected to deviate from schedules by $6.4 \%$ compared to the regular service (Route 67). This indicates that schedulers at STM did not estimate route 467 running time as correctly as done for Route 67 buses. Northbound running time deviation is $2.7 \%$ less than southbound, which indicates that buses are saving more time while traveling north than is expected in the schedules. Buses using reserved lanes are found to have a statistically significant positive effect on running time deviation, decreasing it by $4.4 \%$. This indicates that, on average, buses using reserved lanes are gaining time against their schedules in comparison to other buses.

The presences of articulated buses along the corridor led to an increase by $5.3 \%$ for all bus running time deviation, while the use of an articulated bus decreases the previous value by $0.9 \%$ to reach $4.4 \%$. By adding the running time deviation due to the use of articulated buses' third door (with an average of 2.8 passengers), the use of articulated buses deviates the actual running time from schedules by $6.6 \%$, while keeping all other variables constant at their mean values. This indicates both that there is a problem in scheduling and that articulated buses have powerful effects on running time delays as well as unexpected effects on other buses' running 
time delays. This deviation from schedule can be understood due to two factors. The first is the high frequency of service along the two routes, with the average headway for Route 467 and 67 being less than 7 minutes during the peak hours. The second is the fact that both routes are serving the same passengers at the same stops. Therefore, in many cases buses are directly behind each other, which negatively affect the service. Finally, at the segment level, the presences of TSP outfitted buses along the corridor increases running time deviation from schedules by $0.5 \%$ for all buses along the corridor. While for the TSP equipped buses there was no significant effect on running time deviation.

Table 3: Segment running time and segment runtime deviation (\%) models

\begin{tabular}{|c|c|c|c|c|}
\hline \multirow{2}{*}{ Variable } & \multicolumn{2}{|c|}{ Segment running time } & \multicolumn{2}{|c|}{ Running time deviation (\%) } \\
\hline & Coefficients & $t$-stat & Coefficients & t-stat \\
\hline (Constant) & $361.23 * * *$ & 405.12 & $73.43 * * *$ & 279.76 \\
\hline Actual stops & $10.53 * * *$ & 79.71 & $3.48 * * *$ & 89.57 \\
\hline Segment passenger activity & $1.62 * * *$ & 183.39 & $0.31 * * *$ & 119.88 \\
\hline Articulated rear door activity & $-3.17 * * *$ & -48.87 & $0.36 * * *$ & 18.96 \\
\hline Precip (mm) & $0.14 * * *$ & 7.82 & $0.02 * * *$ & 4.39 \\
\hline Snow $(\mathrm{cm})$ & $0.37 * * *$ & 21.05 & $0.12 * * *$ & 23.88 \\
\hline Route 467 & $-12.40 * * *$ & -20.94 & $6.39 * * *$ & 36.66 \\
\hline Northbound & $-14.59 * * *$ & -60.17 & $-2.72 * * *$ & -38.16 \\
\hline Delay at the start (s) & $-\mathbf{0 . 0 7} * * *$ & -72.65 & $-0.02 * * *$ & -71.50 \\
\hline AM Peak & $-8.22 * * *$ & -23.66 & $-0.76 * * *$ & -7.39 \\
\hline PM Peak & $15.10 * * *$ & 43.71 & $-3.36 * * *$ & -33.00 \\
\hline Night & $-22.97 * * *$ & -64.75 & $-1.45 * * *$ & -13.86 \\
\hline Midnight and early morning & $-48.21 * * *$ & -90.22 & $-0.27 *$ & -1.72 \\
\hline Smart card start & $3.14 * * *$ & 7.41 & $0.83 * * *$ & 6.61 \\
\hline Smart card by the end of 2008 & $12.96 * * *$ & 30.57 & $3.10 * * *$ & 24.88 \\
\hline Reserved lane & $-11.43 * * *$ & -29.58 & $-4.37 * * *$ & -38.45 \\
\hline After articulated buses date & $9.10 * * *$ & 22.37 & $5.33 * * *$ & 44.52 \\
\hline Articulated buses & $12.97 * * *$ & 19.24 & $-0.90 * * *$ & -4.52 \\
\hline After TSP date & $-1.37 * *$ & -3.62 & $0.51 * * *$ & 4.59 \\
\hline TSP buses & $-1.40 * * *$ & -2.40 & -0.05 & -0.29 \\
\hline Segment 1 & $-41.64 * * *$ & -122.65 & $-6.98 * * *$ & -69.87 \\
\hline Segment 3 & $-72.60 * * *$ & -175.44 & $-0.67 * * *$ & -5.51 \\
\hline Segment 4 & $-91.67 * * *$ & -264.93 & $-1.29 * * *$ & -12.69 \\
\hline $\mathrm{N}$ & \multicolumn{2}{|c|}{255,000} & \multicolumn{2}{|l|}{255,000} \\
\hline $\mathrm{R}^{2}$ & \multicolumn{2}{|c|}{0.47} & \multicolumn{2}{|l|}{0.21} \\
\hline F statistic $(22,254977)$ & \multicolumn{2}{|c|}{10057.0} & \multicolumn{2}{|l|}{3087.3} \\
\hline F significance (Prob > F) & \multicolumn{2}{|c|}{0.00} & \multicolumn{2}{|l|}{0.00} \\
\hline $\begin{array}{l}\text { Bold indicate statistical significance } \\
* * * \text { Significant at } 99 \% * * \text { Significan }\end{array}$ & 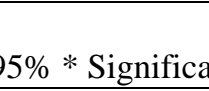 & & & \\
\hline
\end{tabular}




\subsection{CV running time and CV running time deviation models}

The third and fourth linear regression models are developed for the aggregated grouped segments. The third model used the CV of running time multiplied by one hundred as the dependent variable, while the fourth model used the CV of running time deviation multiplied by one hundred as the dependent variable. Table 4 presents the results of these models. The CV running time model contains 478 trip segments' grouped records and explains $45 \%$ of the variation in the running time variation. In this model, variables that have no significant coefficient reveal that they are not positively or negatively affecting the routes' running time variation.

The variance in the number of actual stops made has a statistically significant positive effect, increasing running time variation by $0.06 \%$ for every $1 \%$ increase in the variability of the number of actual stops made along a segment. Therefore, designing segments or routes with fewer stops is generally recommended in order to decrease the running time variation, which is consistent with previous research (El-Geneidy et al., 2011). Every 1\% increase in the variability of the total passengers' activity adds $0.04 \%$ in running time $\mathrm{CV}$, while keeping all other variables constant at their mean values. In addition, variance in articulated buses' passenger activity has a positive coefficient, increasing the running time variation by $0.05 \%$ for every $1 \%$ increase in articulated buses passenger activity.

Variance in snow precipitation increases buses running time variation by $0.002 \%$ for every $1 \%$ increase in snow variance, decreasing the attractiveness of the service. The running time variability for northbound buses is larger by $0.4 \%$ than for southbound buses. This indicates that while the northbound buses are much faster than the southbound buses (as indicated by the running time model), they are experiencing a higher level of variability in running time, requiring schedulers to deal with this degree of variability with more attention in order to improve the service reliability. Midnight and early morning trips experience less variability than midday trips by $0.6 \%$, indicating that they are faster and have more stable running time over time.

The implementation of smart card fare collection system by the end of 2008 increased running time variability by $0.7 \%$, due to the growth in the number of smart card users compared to users of traditional flash passes, making schedulers' task of minimizing variation along the corridor more difficult. While buses that use reserved lanes are faster by 11 seconds (as indicated by the running time model), they experience more variance in their travel time by $0.5 \%$ compared to buses that do not use reserved lanes. This variance can be related to the no turn on red policy where private cars often wait in the reserved lanes in order to turn right at a traffic light (Surprenant-Legault \& El-Geneidy, 2011).

$\mathrm{CV}$ of running time for articulated buses is $2.8 \%$ less than regular busses. However, this value does not account for the true effect of an articulated bus on the running time variation. Hence, the model include a ' $C V$ articulated passenger activity' variable which captures the increases in running time variation due to the increase in articulated buses passenger activity coefficient of variation. Therefore, for every $1 \%$ increase in articulated buses passenger activity coefficient of variation, the running time variation increases by $0.09 \%$, and since the average articulated buses passenger activity coefficient of variation is $21 \%$ (as indicated by the summary 
statistics), this indicates a total increase in running time variation by $1.9 \%$. Accordingly, operating an articulated bus decreases the running time variation by $0.9 \%$.This indicates that while articulated buses increase running time by 13 seconds per trip segment; they experience less variation in their running time. In other words, articulated buses are slower with low variance in running time compared to regular buses making them easier to predict.

Segments one, three and four have a positive coefficient, decreasing running time variance in comparison with segment number two, by $1.2 \%, 3.4 \%$ and $1.8 \%$. This finding indicates that buses are taking less running time along these segments with high level of variance compared to segment number two. While TSP equipped buses have no significant impact on buses running time variation, the presence of TSP buses along the corridor increased all buses running time variation by $0.5 \%$, which means that not all buses are benefiting equally from the TSP system. This indicates a negative effect of the operation of TSP equipped buses on all buses' running time variation along the corridor. According to previous research, TSP benefits are not consistent on running time and running time variation (Kimpel et al., 2005). Therefore, another detailed study is required to investigate the operated TSP system components and operation in order to maximize its benefits for not only TSP equipped buses but also for all buses using the same corridor.

Finally, while smart card start, Route 467 and after articulated buses date variables have a significant coefficient affecting the average running time per trip segments (as indicated by the running time model), they did not show a significant effect on running time variation. This indicates that these strategies' influences are limited to the mean value of running time changes, with neutral effects on variation. In other words, the variation before and after the implementation of a smart card, the limited-stop bus service (Route 467), and the presence of articulated buses along the corridor is the same. 
Table 4: CV segment running time and CV segment running time deviation (\%) models

\begin{tabular}{|c|c|c|c|c|}
\hline \multirow[t]{2}{*}{ Variable } & \multicolumn{2}{|c|}{ CV running time (\%) } & \multicolumn{2}{|c|}{$\begin{array}{l}\text { CV running time deviation } \\
(\%)\end{array}$} \\
\hline & Coefficients & t-stat & Coefficients & t-stat \\
\hline (Constant) & $10.354 * * *$ & 9.58 & $9.332 * * *$ & 6.42 \\
\hline CV actual stops & $0.063 * *$ & 2.32 & $0.126 * * *$ & 3.43 \\
\hline CV passenger activity & $0.042 * *$ & 2.15 & 0.037 & 1.40 \\
\hline CV articulated passenger activity & $0.054 * *$ & 2.24 & $0.061 *$ & 1.86 \\
\hline CV precip & -0.006 & -1.49 & -0.003 & -0.60 \\
\hline CV snow & $0.002 * * *$ & 2.56 & $0.003 * *$ & 2.50 \\
\hline Route 467 & 0.257 & 0.75 & $1.809 * * *$ & 3.91 \\
\hline Northbound & $0.444 * * *$ & 2.79 & -0.187 & -0.87 \\
\hline CV delay at the start & 0.001 & 1.25 & 0.001 & 1.60 \\
\hline AM Peak & -0.189 & -0.89 & $-0.479 *$ & -1.69 \\
\hline PM Peak & 0.336 & 1.41 & 0.480 & 1.50 \\
\hline Night & -0.292 & -1.12 & $-0.664 *$ & -1.89 \\
\hline Midnight and early morning & $-0.561 *$ & -1.68 & -0.205 & -0.46 \\
\hline Smart card start & -0.018 & -0.04 & -0.107 & -0.20 \\
\hline Smart card by the end of 2008 & $0.670 * *$ & 1.97 & $1.185 * *$ & 2.53 \\
\hline Reserved lane & $0.486 * *$ & 2.46 & 0.198 & 0.75 \\
\hline After articulated buses date & 0.048 & 0.19 & $-0.997 * * *$ & -2.94 \\
\hline Articulated buses & $-2.752 * *$ & -2.18 & $-3.475 * *$ & -2.05 \\
\hline After TSP date & $0.453 * *$ & 1.97 & $0.583 *$ & 1.89 \\
\hline TSP buses & 0.236 & 0.87 & 0.295 & 0.80 \\
\hline Segment 1 & $1.183 * * *$ & 5.58 & $1.716 * * *$ & 6.02 \\
\hline Segment 3 & $3.377 * * *$ & 14.82 & $3.403 * * *$ & 11.11 \\
\hline Segment 4 & $1.178 * * *$ & 5.50 & $1.684 * * *$ & 5.86 \\
\hline $\mathrm{N}$ & \multicolumn{2}{|c|}{478} & \multicolumn{2}{|c|}{478} \\
\hline $\mathrm{R}^{2}$ & \multicolumn{2}{|c|}{0.45} & \multicolumn{2}{|c|}{0.35} \\
\hline F statistic $(22,455)$ & \multicolumn{2}{|c|}{16.91} & \multicolumn{2}{|c|}{11.11} \\
\hline F significance $($ Prob > F) & \multicolumn{2}{|c|}{0.00} & \multicolumn{2}{|c|}{0.00} \\
\hline
\end{tabular}

Bold indicate statistical significance

*** Significant at $99 \% * *$ Significant at $95 \% *$ Significant at $90 \%$

The fourth model is the CV of running time deviation (\%). It contains 478 trip segment patterns and explains $35 \%$ of the variation in the CV of running time deviation from schedules. In this model, variables that have no significant coefficient reveal that they are neither positively nor negatively affecting the variation in running time deviation from schedules. The CV of running time deviation (\%) model is generated to understand the difference between the trip segments' running time range of variation and the schedules' permitted level of variation. Generally, it is expected that factors affecting CV of the running time deviation should have the same sign and magnitude as the previous model. However, inconsistency between the two 
models may be interpreted in terms of schedules design, and the unanticipated events that are facing schedulers in relation to service variation.

The variance in the number of actual stops increases the variance in running time deviation from schedules by $0.1 \%$ for every additional $1 \%$ increase in the variance of the number of actual stops made. Therefore, designing segments with fewer stops is generally recommended in order to decrease the variation in the deviation from schedules. This is consistent with the previous model. The variance in articulated buses' passenger activity has a positive coefficient value. For every $1 \%$ increase in variance of articulated buses' passenger activity, the variance of running time deviation from schedules increases by $0.06 \%$. Every $1 \%$ increase in snow precipitation variance increases the variance of running time deviation from schedule by $0.003 \%$. AM peak and night trips are experiencing less variability in their travel time deviation from the schedules by 0.5 and $0.7 \%$, respectively, compared to midday trips, indicating that these trips are more consistent in their travel time.

At the segment level, the limited-stop bus service (Route 467) is experiencing higher levels of variance on running time deviation from schedule than Route 67 by $1.8 \%$. This demonstrates that Route 467 buses, while they are faster than Route 67 by 12.4 seconds per segment (as indicated by the first model), are experiencing a 6.4\% higher running time deviation (as indicated by the second model), with a $2 \%$ higher range of variance in deviation from schedules. This high variance in the deviation from schedules for Route 467 indicates a scheduling issue that requires further investigations. Furthermore, by the end of 2008, the implementation of smart cards increased the variance of running time deviation from schedules by $1.2 \%$. This indicates unanticipated difficulty in relation to the implantation of smart cards on service variation.

After the introduction of articulated buses along the corridor, the variance in deviation from schedules for all buses decreased by $0.99 \%$. This means that the variance in deviation from schedule has decreased for all buses, so the service provided is currently more reliable overtime due to the presence of articulated buses. For articulated buses, this range of running time deviation from schedules decreased by $3.5 \%$ to reach $4.5 \%$, indicating more consistency in the amount of deviation from schedules. Nevertheless, by subtracting the previous value from articulated buses' passenger activity variance in deviation this indicates that the operation of an articulated bus decreases the range of running time deviation from schedules by $2.5 \%$.

After the introduction of a few TSP equipped buses along Route 467, all buses along the corridor have suffered from increase in the variance in running time deviation from schedules by $0.6 \%$. This indicates that some times the time saving which has been achieved after the introduction of TSP equipped buses along the corridor diminishes due to the higher level of added variation. For TSP equipped buses no significant difference was present when compared to other buses. Furthermore, while reserved lanes decrease bus running time by 11 seconds, they increase the range of running time variation by $0.5 \%$. However, this increase in running time variation is not affecting deviation from schedules variation. This may be due to the design of schedules which mitigates this range of variation. 


\section{Conclusion}

Various measures have been implemented by STM along boulevard Saint-Michel between 2007 and 2011. These measures include the implementation of a smart card fare collection system 'OPUS', limited-stop bus service (Route 467), reserved bus lanes, introduction of articulated buses, and TSP. The main objective of this article is to understand the impact of these measures on bus running time variation, while acknowledging that these variations effect the running time deviation from schedules at the segment level. It analyzes archived data obtained from STM's AVL and APC systems for Route 67 and 467, using four statistical models. The first and second models were for disaggregated trip segments, investigating the implemented strategies' effects on running time and running time deviation from schedules. The third and fourth models were for the aggregated grouped trip segments level, examining the implemented strategies' effects on running time variation and on variation in running time deviation from schedule.

At the segment level, the introduction of a smart card fare collection system increased bus running time by 16.1 seconds (or by 3.8\% compared to Route 67 initial situation), increased running time deviation from scheduled by $3.9 \%$, increased running time variation by $0.7 \%$, and significantly increased variation in running time deviation from schedule by $1.1 \%$. This indicates an unanticipated problem in relation to the implementation of smart cards on service provision and variation that need to be addressed by adding more recovery time as well as running time to the schedules. The articulated buses saw an increase in running time by 13 seconds (3.1\%) on average per segment accompanied by an increase in running time deviation from schedule of $6.6 \%$. Furthermore, articulated buses were subjected to a decrease in running time variation by $0.9 \%$ compared to other buses, and a decrease in variation in running time deviation from schedule by $2.5 \%$. This indicates that articulated buses are more consistently slower and behind schedule than other buses. Therefore, transit agencies planning to use articulated buses in general are required to provide more running time and less recovery time compared to other bus types. Meanwhile, the presence of articulated buses in the corridor had a negative impact on running time for other buses increasing it by 9 seconds (2.2\%) per trip segment, as well as increasing their deviation from schedules by 5.3\%. This increase is suggested to be stable since the coefficient of variation of running time deviation from schedules has decreased by $0.99 \%$, with no significant effect on running time variation. Therefore, it is expected that regular buses running parallel to articulated buses will be consistently late, requiring adjustments in schedules.

While the operation of an exclusive bus lane during the peak hours saved an average of 11 seconds (2.7\%) for buses utilizing these lanes and decreased running time deviation from schedules by $4.3 \%$, these buses experience more variance in their travel time $(0.5 \%$ more than buses not using these lanes). This can be interpreted to the effects of the cue of cars in front of the bus since Montreal has no turn on red policy. This can be solved, to a degree, by moving stops to intersections far side locations as well as prohibiting some right turns along the corridor. The TSP equipped buses are faster than other buses by 1.4 seconds $(0.3 \%)$ per trip segments compared to other buses after the introduction TSP; however, they have no significant effect on running time deviation from schedule, running time variation, and variation in running time deviation from schedules. Accordingly, the scheduled running time for TSP equipped buses can be decreased slightly without affecting the variation in service. On the other hand, the presence of TSP equipped buses along the corridor had an impact on all other non-TSP equipped buses 
where running time declined for all buses by 1.37 seconds (0.3\%) per trip segment. However, these buses suffered a $0.5 \%$ increase in their running time variance, and a $0.6 \%$ increase in variation of running time deviations from schedules. The mixing between TSP equipped and non-TSP equipped in a route is not recommended at high frequency routes due to the impact on running time variation; as such variation will cause a decline in the reliability of service and will require additions in recovery time, diminishing their running time savings.

At the segment level, the limited-stop bus service (Route 467) is faster by 12.4 seconds (3.0\%) and with no significant difference in running time variation compared to the regular service (Route 67). However, Route 467 buses exhibit 6.4\% higher running time deviation from schedules, as well as $1.8 \%$ higher variance in running time deviation from schedules. This indicates that while the use of limited-stop service is recommended due to running time saving and little impacts on running time variation, schedule revisions are needed to add more recovery time for Route 467 similar to the amount of recovery time that exist for Route 67. Finally, the results of this research point out to some key elements to consider in the formulation of policies for promoting the use of various improvement strategies along high frequency routes.

- This study has shown that use of a smart card fare collection system, in comparison with the use of traditional flash passes, increases bus running time, running time variation and variation of deviation from schedules. This indicates less efficiency and decline in reliability of bus transit service associated with the use of the smart cards fare collection system compared to the use of traditional flash passes, which can be related to the type of technology being adopted. Yet it is important to note that using smart card can have other benefits that can out weight the loss in travel time, for example reduction in fare evasion and/or easy transfer between the different transit systems in the region.

- The use of reserved bus lanes, while it improves running time significantly, it intensifies running time variation. Therefore, a clear understanding of the location of reserved bus lanes and bus stops are required, particularly in cities that have no turn on red policy as the case of Montreal.

- The use of articulated buses increases running time and running time deviation from schedules, while it improves running time variation and deviation variation, providing more consistent service. In other words, articulated buses are slower with low variance in running time compared to regular buses making them easier to predict. Therefore, transit agencies planning to use articulated buses in general are required to provide more running time and less recovery time compared to other bus types.

- Furthermore, due to the presence of articulated buses in the corridor regular buses running in parallel are affected by this presence. A negative spillover effect was observed in our study leading to increase in running times and deviation from schedules among regular buses. However, less variation of deviation from schedules is expected, with no changes in running time variation. Therefore, it is expected that regular buses running parallel to articulated buses will be consistently late, so adjustments in scheduled running time is recommended if the agency is planning on mixing articulated with non-articulated buses in a route, although this action is not a preferred one. 
- The use of limited stop bus has a positive (decreasing) effect on running time with no significant effect on running time variation, although it increases running time deviation and variance of deviation from schedules. This indicates a few benefits of using limited stop bus service and signifies a problem in scheduling. Therefore, using limited-stop bus service is recommended with a caution associated with designing the schedules.

- The operation of TSP equipped buses improves running time with no significant effect on running time variation and variation of deviation from schedules, compared to other non-TSP equipped buses. On the other hand, TSP equipped buses had a mixed effect on non-TSP equipped buses. The first is a positive effect leading to running time savings for non-TSP buses. The second is a negative effect increasing other buses' running time variation and deviation variation. Therefore, to avoid such increases in service variation in the future, mixing TSP buses and non-TSP buses is not recommended along high frequency routes.

Finally, it was not possible to calculate the headway distribution with the current data used in this study since not all STM's buses are equipped with APC and AVL systems. Therefore, it is recommended developing future studies that investigate the effects of these measures on the headway variation using the same methodology. In addition, further investigations to understand the connection between the impacts of these changes on system performance and passengers' perception are recommended.

\section{Acknowledgements}

We would like to acknowledge Michel Tremblay, Jocelyn Grondines and Sébastien Gagné from the Société de transport de Montréal (STM) for providing the data used in the project and support during this project. This research was funded by Natural Sciences and Engineering Research Council of Canada-collaborative research and development (NSERCCRD) program. Last but not least we would like to thank the two anonymous reviewers for their valuable feedback. 


\section{REFERENCES}

Abkowitz, M. (1983). The transit Service Reliability Problem and Potential Solutions. Proceedings of the August 1982 Transit Reliability Workshop USDOT Urban Mass Transportation Administration.

Abkowitz, M., \& Engelstein, I. (1983). Factors affecting running time on transit routes. Transportation Research Part A, 17(2), 107-113.

American Public Transportation Association. (2011a). 2011 Public transportation fact book (62nd ed.). Washington: American Public Transportation Association (APTA).

American Public Transportation Association. (2011b). Transit ridership report First Quarter 2011. Washington: American Public Transportation Association (APTA).

Balcombe, R., Mackett, R., Paulley, N., Preston, J., Shires, J., Titheridge, H., ... White, P. (2004). The demand for public transport: A practical guide (Vol. TRL 593). Berkshire, United Kingdom: UK's Transport Research Laboratory (TRL).

Bates, J., Polak, J., Jones, P., \& Cook, A. (2001). The valuation of reliability for personal travel. Transportation Research Part E: Logistics and Transportation Review, 37(2-3), 191229. doi: 10.1016/s1366-5545(00)00011-9

Boyle, D. (2006). Fixed-route transit ridership forecasting and service planning methods TCRP Synthesis 66. Washington, DC: Transportation Research Board.

Camus, R., Longo, G., \& Macorini, C. (2005) Estimation of transit reliability level-of-service based on automatic vehicle location data. (pp. 277-286).

Chen, C., Skabardonis, A., \& Varaiya, P. (2003). Travel-Time reliability as a measure of service. Transportation Research Record: Journal of the Transportation Research Board, 1855(1), 74-79. doi: 10.3141/1855-09

Chen, X., Yu, L., Zhang, Y., \& Guo, J. (2009). Analyzing urban bus service reliability at the stop, route, and network levels. Transportation Research Part A: Policy and Practice, 43(8), 722-734.

Daskalakis, N., \& Stathopoulos, A. (2008). Users' perceptive evaluation of bus arrival time deviations in stochastic networks. Journal of Public Transportation, 11(4), 25-38.

Diab, E., \& El-Geneidy, A. (2012). Understanding the impacts of a combination of service improvement strategies on bus running time and passenger's perception. Transportation Research Part A: Policy and Practice, 46(3), 614-625.

El-Geneidy, A., Horning, J., \& Krizek, K. (2011). Analyzing transit service reliability using detailed data from automatic vehicular locator systems. Journal of Advanced Transportation, 45(1), 66-79.

El-Geneidy, A., Strathman, J., Kimpel, T., \& Crout, D. (2006). The effects of bus stop consolidation on passenger activity and transit operations. Transportation Research Record, 1971, 32-41.

El-Geneidy, A., \& Surprenant-Legault, J. (2010). Limited-stop bus service: An evaluation of an implementation strategy. Public Transport: Planning and Operation, 2(4), 291-306.

Fu, L., \& Yaping, X. (2007). A new performance index for evaluating transit quality of service. Journal of Public Transportation, 10(3), 47-70.

Hensher, D. A., Stopher, P., \& Bullock, P. (2003). Service quality-developing a service quality index in the provision of commercial bus contracts. Transportation Research Part A, 37, 499-517. 
Hollander, Y. (2006). Direct versus indirect models for the effects of unreliability. Transportation Research Part A: Policy and Practice, 40(9), 699-711. doi: 10.1016/j.tra.2005.12.007

Kimpel, T. (2001). Time point-level analysis of transit service reliability and passenger demand. Doctor of Philosophy in Urban Studies, Portland State University, Portland, OR.

Kimpel, T., Strathman, J., Bertini, R., Bender, P., \& Callas, S. (2005). Analysis of transit signal priority using archived TriMet bus dispatch system data. Transportation Research Record(1925), 156-166.

Kittelson \& Associates, KFH Group, Parsons Brinckerhoff Quade \& Douglass, \& HunterZaworsk, K. (2003). Transit Capacity and Quality of Service Manual. In n. Edition (Ed.). Washington D.C., USA.: TRB Transportation Research Board.

Koenig, J. (1980). Indicators of urban accessibility: Theory and application. Transportation, 9, $145-172$.

Levinson, H. (1983). Analyzing transit travel time performance. Transportation Research Record, 915, 1-6.

Lin, J., Wang, P., \& Barnum, D. (2008). A quality control framework for bus schedule reliability. Transportation Research Part E, 44(1), 1086-1098.

Murray, A., \& Wu, X. (2003). Accessibility tradeoffs in public transit planning. [Article]. Journal of Geographical Systems, 5(1), 93-107.

Nam, D., Park, D., \& Khamkongkhun, A. (2005). Estimation of value of travel time reliability. Journal of Advanced Transportation, 39(1), 39-61. doi: 10.1002/atr.5670390105

Noland, R., \& Polak, J. (2002). Travel time variability: A review of theoretical and empirical issues. Transport Reviews, 22(1), 39-54.

Perk, V., Flynn, J., \& Volinski, J. (2008). Transit Ridership, Reliability, and Retention. Florida: National Center For Transit Research (NCTR), University of South Florida.

Pinjari, A., \& Bhat, C. (2006). Nonlinearity of response to level-of-service variables in travel mode choice models. Transportation Research Record: Journal of the Transportation Research Board, 1977(-1), 67-74. doi: 10.3141/1977-11

Saberi, M., Zockaie, A., Feng, W., \& El-Geneidy, A. (2012). Definition and properties of alternative bus service reliability measures at the stop level. Paper presented at the 91th Annual Meeting of the Transportation Research Board, Washington, DC.

Schramm, L., Watkins, K., \& Rutherford, S. (2010). Features that affect variability of travel time on bus rapid transit systems. Transportation Research Record: Journal of the Transportation Research Board, 2143(-1), 77-84. doi: 10.3141/2143-10

Société de transport de Montréal. (2009). The STM in 2008 activity report Montreal, Québec: Société de transport de Montréal.

Société de transport de Montréal. (2010). On the move 2009 activity report Montreal, Québec: Société de transport de Montréal.

Société de Transport de Montréal. (2011). The 467 Express, a taste of tomorrow’s transit Retrieved 11th July, 2011, from http://www.stm.info/english/info/a-467.htm

Sterman, B., \& Schofer, J. (1976). Factors affecting reliability of urban bus services. Transportation Engineering Journal, 102(1), 147-159.

Strathman, J., Dueker, K. J., Kimpel, T. J., Gerhart, R. L., Turner, K., Taylor, P., . . Griffin, D. (2000). Service reliability impacts of computer-aided dispatching and automatic location technology: A Tri-Met case study. Transportation Quarterly, 54(3), 85-102. 
Surprenant-Legault, J., \& El-Geneidy, A. (2011). Introduction of a reserved bus lane: Impact on bus running time and on-time performance. Paper presented at the the 90th Transportation Research Board Annual Meeting.

Tann, H., \& Hinebaugh, D. (2009). Characteristics of bus rapid transit for decision-making. Washington, DC: Federal Transit Administration, U.S. Department of Transportation.

Tétreault, P., \& El-Geneidy, A. (2010). Estimating bus run times for new limited-stop service using archived AVL and APC data. Transportation Research: Part A, 44(6), 390-402. 